\title{
The semiotic sense of context vs the material sense of context
}

\author{
Wendy L. Bowcher
}

Correspondence:

wendylee@mail.sysu.edu.cn Sun Yat-sen University, Guangzhou, China

\begin{abstract}
This paper investigates the relationship between culture and language through analyzing material and semiotic features in a context of language-in-use. The paper first discusses what is meant by 'material' and 'semiotic' context from an SFL perspective. It then investigates the way in which these two 'senses' of context may converge within a specific instance, affecting interaction in a subtle way and together construing a cultural phenomenon.
\end{abstract}

Keywords: Material context, Material Situational Setting (MSS), Semiotic context, Context of situation, Cultural context

\section{Introduction}

The title of this paper derives from a selection of titles, some of which included the abbreviation 'vs' between two concepts, given to me to choose from as a title for a presentation at the inaugural Halliday and Hasan Forum held at Guangdong University of Foreign Studies in December 2016. ${ }^{1}$ I chose the title "the semiotic sense of contexts vs the material sense of context" as it related most closely to my interest in the concept of context in Systemic Functional Linguistics (SFL). Although the use of 'vs' (versus) is not used in SFL when describing these two perspectives on context, this seemed to be an interesting way of considering the two perspectives. We find the term ' $v$ s' in a number of contexts: sports is perhaps one of the most common fields, and legal language abounds with the term vs - e.g. Rogers vs Smith. However, there is another meaning of 'versus': "as compared to or as one of two choices; in contrast with" (Dictionary.com). Thus, placing 'vs' between the two 'senses' of context suggests that these represent opposite context 'poles', perhaps are even at odds with each other and that there is little likelihood of there being any overlap or middle ground between them. My presentation at the Forum included a broad sweep of the concept of context in SFL theory, taking in recent thinking on various aspects of the material and semiotic in the context of language in use. In this paper, however, I focus on the question of whether the material context and semiotic context are indeed separate phenomena, and on how they may relate to each other. In order to answer this two-part question, I conduct an analysis of a short text and demonstrate in a localized and detailed way how the material and the semiotic may converge and at times together depend on and reach into the cultural context in which the situation is embedded. Before conducting the analysis, I describe what could be considered the two different 'senses' of context from an SFL perspective.

(c) The Author(s). 2018 Open Access This article is distributed under the terms of the Creative Commons Attribution 4.0 International License (http://creativecommons.org/licenses/by/4.0/), which permits unrestricted use, distribution, and reproduction in any medium, provided you give appropriate credit to the original author(s) and the source, provide a link to the Creative Commons license, and indicate if changes were made. 


\section{Context in relation to language: the SFL model of context}

Ervin-Tripp quite rightly commented that in research on the relationship between context and language, (she referred to it as 'context in language'), "context gets into language mainly by reference. We talk about the context" (1996: 21). Indeed, there is much talk about context across a variety of approaches to the study of language. However, when it comes to an understanding of the relationship between context and language, much academic research and description rests on intuition. This intuition might be framed in seemingly 'scientific' terms, but it is intuition all the same and this has an important bearing on what one DOES with context, how one models it, and how one ANALYSES context in any communicative situation.

In SFL theory, context is an analytical level of description. It is one of the resources drawn upon for investigating the nature of the language system, for describing language variation and for understanding the role of language as social activity. Further, language in use (language in context) is the site where observations about the nature of the language system can be made, where one can understand how the system may be altered and how it is maintained. It is argued that an instance of the language system (language put to some use) correlates with an instantiation of the social system (a context of situation), the two working in a symbiotic relationship. SFL theory models the relations between language and context and instance and system in terms of realization and construal and across several strata, as illustrated in Fig. 1 adapted from Halliday (2007: 275).

Across the horizontal axis of Fig. 1 is the relation of instantiation; that is, the potential $\leftrightarrow$ instance continuum; the social system is instantiated in a specific context of situation and the language system is instantiated in a text. The vertical axis of the figure shows the relation of realization/construal. The social system is realized in language and language construes the social system. Likewise, a text construes a context of situation while a context of situation is realized in a text. Below right of the term 'language system' are the four strata of language: semantics, lexicogrammar, phonology and phonetics. The latter two strata are the expression form of language and hold a very different realizational relation between each other and with the other strata than those of semantics and lexicogrammar, which are the content of language. The content

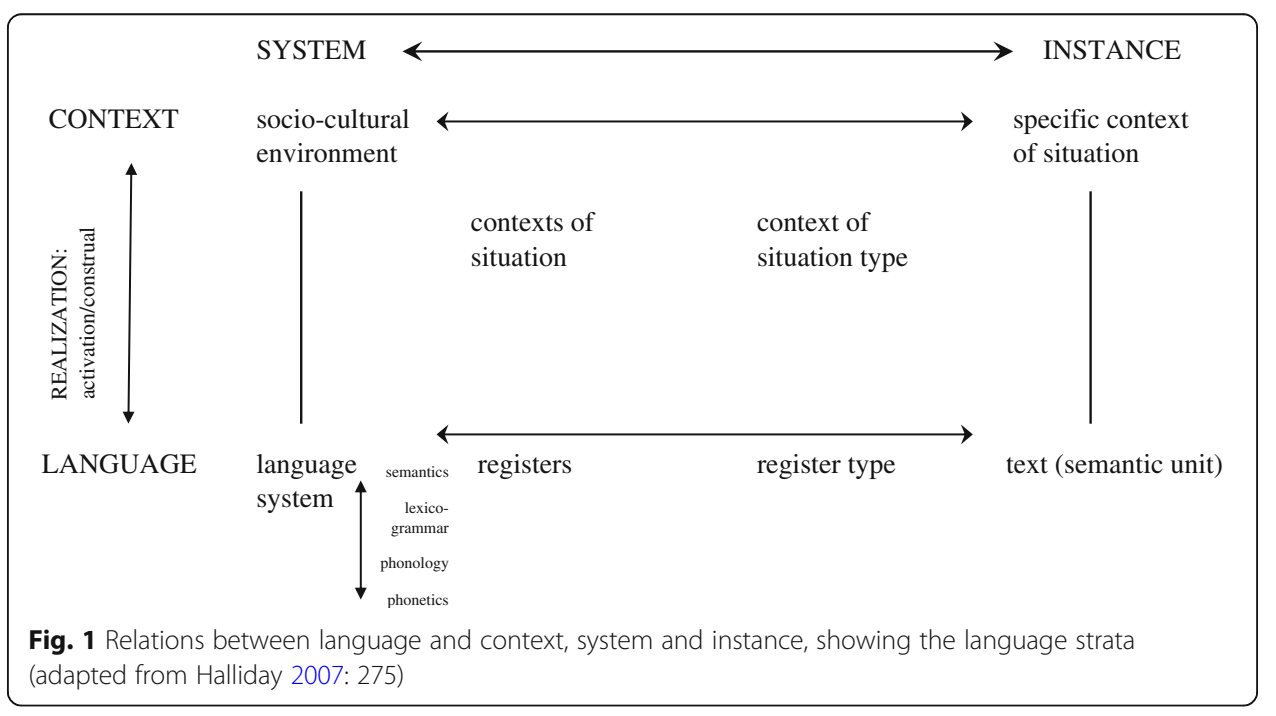


strata of language play the most significant role in the realization of context as text. The expression form of language is just that - it is the "material" or "physical" means of communicating, the sounds or markings on a page whereby the inner meanings and organization of those meanings are coded into a conventionalized output system. This concept of material is not the focus of the investigation in this article. Rather, we are investigating materiality within the surrounding context, which encompasses a much broader domain than the expression form of language.

Understanding how 'text' is conceptualized, and perhaps, how it is NOT conceptualized in SFL is important to understanding the concept of context. Unlike many approaches, text is not conceptualized as strings of words and sentences. It is not simply a unit that is bigger than a sentence (cf. Halliday 1985: 10). Rather, a text is "an instance of social meaning" (Halliday 1985: 11). For sure, this instance of social meaning requires some means of expression, and for this we need an intersubjective medium of communication, a conventionalized coding system, which can be considered as the text as product, an "output, something that can be recorded and studied, having a certain construction that can be represented in systematic terms" (Halliday 1985: 10). However, texts do not come into being in isolation from their contexts (cf. Hasan 2001). The very fact that a text is an instance of social meaning "presupposes" some kind of social context (cf. Hasan 2001), and social contexts, when "filtered" through language comprise three features which interactants are typically compelled to attend to:

i: The nature of the social process - what is being achieved through the acts of verbal meaning;

ii: The nature of the relationship between the interactants;

iii: The nature of the code for message transmission (Hasan 1981: 108)

These three features are captured in the concept of 'context of situation' as abstract domains of potentially relevant features: Field, Tenor and Mode respectively. These domains are not material, and not descriptions of a situation's 'spatio-temporal' character, although either of these aspects may be relevant to the meanings expressed through the language used within a given situation when they are 'semioticised' within the situation. The unique aspect of the SFL model of context and language is that the features of context of situation which fall within the domains of Field, Tenor, and Mode, are semiotic in nature and are theoretically motivated with respect to the language system. They are semiotic in nature because context of situation itself is a semiotic construct - it is a construct of meaning relations.

What does it mean to say that the domains of Field, Tenor, and Mode are theoretically motivated with respect to the language system? The answer to this question lies in the relationship between the content strata of language and the extralinguistic stratum of context. Halliday has hypothesized that language is a social activity and is multifunctional in nature; it is used to construe experience (Field), to make sense of and organize that experience (Mode), and at the same time to enact the social relations of the situation (Tenor). At the linguistic level, and specifically at the level of meaning (semantics), multifunctionality is described in terms of three metafunctions: ideational, textual and interpersonal respectively. There is "a systematic prehension between the linguistic metafunctions" and the lexicogrammar of language (Hasan 2014: 2) such that for English, the ideational metafunction is 
primarily realized in choices in the lexicogrammatical system of TRANSITIVITY, the textual in systems of THEME and INFORMATION, and the interpersonal in systems of MOOD. Thus, there is a functional "hook-up" among features of the language system and the contextual systems (Hasan 1995). Hasan (2014) later refers to this as a "resonance" or context-metafunction resonance (CMR) because features of linguistic strata are not in a direct causal relation with context but a probabilistic one showing systematic patterning.

\section{The material and semiotic senses of context}

So far I have focused on how context is theoretically conceptualized in SFL, and some of the relations this concept holds with other concepts within the theory. Let us now return to the senses of context as mentioned in the title of this paper; the semiotic and the material. The semiotic sense is considered first.

In a nutshell, and as has already been mentioned, context, and more specifically, context of situation is a semiotic construct. But what exactly does that mean? The word 'semiotic' of course means 'sign' and something can only be a sign if it conveys some kind of meaning; that is the nature of a sign. So when we say that there is a semiotic sense of context, we are talking about contextual features that bear some kind of meaning relevant to the talk that is taking place, that is, those features that simultaneously activate and are realized by specific language choices in a given situation. These are the meanings that interactants 'attend to' in a context in contrast with those that have no bearing on the talk. Halliday explains it in this way:

The social context of language behavior - the situation in which meanings are exchanged - is ... a semiotic construct; and it is perceived as such by those taking part. The interactants in a speech situation treat that situation as embodying aspects of the social order - as having certain potential in terms of which their own acts of meaning will be interpreted and valued. (Halliday 1984: 8)

A typical way of representing context is to model it paradigmatically, i.e. as a system network of options, which aims to achieve a description of the potential conditions of relevant contextual (or social) relations for language in use, those conditions which have the potential to "make a difference" to the language that is involved [cf. (Butt D.: Parameters of context, unpublished): 6]. However, the problem with semiotic features is that such features only bear meaning within the situation in which they are 'activated', or come to life (cf. Bowcher 2014: 181). Elements in any model representing context at the system end of the system-instance continuum are therefore only 'potentially' semiotic, and developing a description of what may be potentially relevant to language-in-use seems like an impossible task. However, those features that interactants attend to in a situation of language use, the Field, Tenor, and Mode, can be generalized into a set of primary systems of Field, Tenor and Mode briefly defined here as:

Field: Action, Sphere of Action, Performance of Action

Tenor: Social Hierarchy, Agentive Role, Social Distance

Mode: Role of Language, Channel, Medium

[see Bowcher 2014; cf. (Butt D.: Parameters of context, unpublished); Hasan 2014]

Essentially, these define what each of these contextual parameters is all about: Field is about the nature of the activity and its content; Tenor is about the nature of the 
participants vis-à-vis one another in the situation and in the text (which is also a part of the situation); Mode is about the nature of the means of communication in the situation and how this affects the role and nature of the language used. Theoretically, through analyses of various corpora of situated language use, reasonably detailed features can become a part of the general descriptive model of context of situation - one which could apply to a range of different situations, and indeed, there is much work underway to this end [e.g. Bowcher 2007, 2014; (Butt D.: Parameters of context, unpublished); Hasan 2014]. However, a model of all potentially semiotic features of context of situation could not realistically be developed, as such a model would end up being an attempt at describing 'everything', and this would be impossible and actually unnecessary for the purposes of discourse analysis.

In contrast with the semiotic features, it seems at first glance that describing the material features of context is less problematic. Wouldn't this simply involve describing the material environment of the talk taking place? However, when one tries to actually choose what to include in a description of the material environment, it quickly becomes evident that it is difficult to know where to begin and where to end - which features and how much detail of those features to include and which features to exclude. For example, is the chair against the wall important to mention in a situation where two people are talking in a room? If so, why? And if not, why not?

In order to delineate the material and semiotic contexts, Hasan has proposed the term Material Situational Setting (MSS). The MSS refers to the "actual physical setting in which a text might unfold" (Hasan 1981: 108), and is irrelevant to the talk insofar as it does not enter the talk. Rather, it remains as a "dormant source for affecting the verbal going on" (Hasan 1981: 110). That is, features of the material context could come into play in the talk of the interactants, and thus become a part of the semiotic contextual description.

The way into deciding which features of either the material or the semiotic context are relevant to a linguistic exchange, according to SFL theory, is to analyze the language that is used, because it is in the language that those features of the semiotic and/or material situational setting are "illuminated" or "leave their trace" (e.g. Hasan 2009). Features from both the semiotic and the material context which do leave a trace in the text are brought within the description of the context of situation, the semiotic context. Hasan puts it this way:

If the term 'context of situation' does not refer to all of human social conditions of existence, to all situation-purport, then some principle for abstraction is needed, as Firth was the first to point out. The principle Halliday provides, from the construal point of view, is that of consulting the text: relevant context is that part of the extralinguistic situation which is illuminated by language-in-use, by the language component of the speech event, the other name for which is text. (Hasan 1995: 219 italics in the original).

Thus, the material sense of context can be thought of as the Material Situational Setting and as a "dormant" source of semiotic potential. The semiotic sense of context is that context that is construed in the language itself, and its features can be organized under the contextual parameters of Field, Tenor and Mode. However, the material 'becomes' semiotic when it is 'illuminated' in the text. 
An example of the way in which features of the MSS become part of the semiotic context is illustrated through analyzing the following exchange (Excerpt One). Here, a young boy, Ben, is instructing (and implicitly criticizing) an adult man, Jack, on how to use "four different garbage cans" in the kitchen:

\section{Excerpt one}

1. Ben: And how about the word, "recycle"? I mean you put the eggshells in with the paper instead of the organic materials.

2. Jack: Oh. Oh. I thought you had just four different garbage cans.

3. Ben: Look, this one is for paper, this one is for aluminum, this one is for glass and this one is for the organic materials like eggshells.

4. Jack: Yes, well, I'll just put the eggshells over here then no problem (from Man of the House, Walt Disney Pictures).

In the text, the nominal group "this one", used four times (see Ben's utterances at no. 3), is a reference to something in the mutually visible environment of the speakers, the material environment. In this case it refers to each of the four garbage cans that Ben is pointing to as he talks with Jack. There is a more oblique reference to the garbage can when Ben says "you put the eggshells in with the paper". In this utterance "in" can be inferred as "in the garbage can that is used for paper" and could be considered a 'trace' of the material environment in the language, whose meaning is 'illuminated' more fully as the dialogue continues. The use of the definite article with "eggshells" and "paper" indicates that these items are identifiable by the speakers and hence within the material environment. So these material elements, and not others in the immediate situation take on meaning within the talk in this situation. It is this kind of reference to the material environment that we most often associate with the way in which features of the MSS enter the semiotic domain of the context of situation. This situation is one in which the language and non-verbal activities are "integrated", and the role of language is described as "facilitating" the activity (e.g. Halliday 1977, 1985).

However, there are other ways that the material context and the semiotic context might be related in a given situation. For instance, in highly institutionalized situations, such as ceremonies and trials in courts of law, features of the material setting and of the semiotic context 'converge': the language used, the location of participants vis-à-vis one another, even possibly the size or appearance of the structures they stand or sit on, their physical postures and behaviors, their clothing, and the location of the event itself, together construe a range of redundant meanings (Bowcher 1999; cf. Hasan 1981). There is also the possibility of the material environment influencing the talk, particularly its flow and organization:

Try helping your child solve a mathematical problem while engaged in cooking a complex dish - there will be hesitations, pauses, repetitions because the material 
situation is 'dividing' speaker attention. The language of the text might then bear traces of MSS, without there being any reference to any specific element of the MSS (Hasan 2009: 189).

Here, we can interpret 'traces' as 'effects' on the flow of the talk.

In the analysis which follows, we will consider another way in which the material environment plays a role in the talk that takes place. Here we will see how the material and the semiotic not only converge but are interdependent upon the cultural context in which the interaction is embedded, such that the interpretation of the linguistic choices made in the situation requires an understanding of the cultural domain. The text is a short dialogue between two friends in a scene from a movie. For the sake of analysis, we suspend reality and treat this scene as 'real' interaction to which we are privy. Indeed, the filmic mode positions the viewer as an observer of the beginning, middle and end of this private conversation. The scene opens with Ben, a young teenage boy, at a cafeteria holding a tray of food and walking away from a canteen buffet towards a table in the

Table 1 Lexicogrammatical and intonation analysis of clauses 1-4

\begin{tabular}{|c|c|c|c|c|}
\hline \multicolumn{2}{|l|}{1 someone } & sure & is & hungry \\
\hline \multicolumn{2}{|l|}{ Carrier } & & $\begin{array}{l}\text { Proc: } \\
\text { Relational }\end{array}$ & Attribute \\
\hline \multicolumn{2}{|l|}{ Subject } & $\begin{array}{l}\text { Mood Adjunct } \\
\text { (intensity) }\end{array}$ & Finite & Complement \\
\hline \multicolumn{2}{|l|}{ Theme } & Rheme & & \\
\hline \multicolumn{5}{|c|}{ // 53 Someone /sure is /hungry // } \\
\hline \multirow[t]{3}{*}{2 hey } & Monroe & how & [are] & doing \\
\hline & & $\begin{array}{l}\text { Circumstance } \\
\text { (manner) }\end{array}$ & [proc] & $\begin{array}{l}\text { Actor Proc: } \\
\\
\text { Material }\end{array}$ \\
\hline & Vocative & Adjunct & [Finite] & Subject Predicator \\
\hline Theme (textual) & $\begin{array}{l}\text { Theme (interpersonal) } \\
\text { (vocative) }\end{array}$ & Theme (topical) & Rheme & \\
\hline \multicolumn{5}{|l|}{ Theme } \\
\hline \multicolumn{2}{|l|}{ //13 Hey Mon/roe // } & \multicolumn{3}{|l|}{ //1 how you /doing// } \\
\hline 3 don't & they & feed & you & at home \\
\hline Proc: Material & Actor & $\begin{array}{l}\text { Proc: Material } \\
\text { (cont...) }\end{array}$ & Goal & Cir: Location \\
\hline $\begin{array}{l}\text { Finite }+ \text { mood Adjunct } \\
\text { (neg) }\end{array}$ & Subject & Predicator & Complement & Adjunct \\
\hline Theme (interpersonal) & Theme (topical) & Rheme & & \\
\hline \multicolumn{5}{|l|}{ Theme } \\
\hline \multicolumn{5}{|c|}{ //2 Don't they /feed you at /home// } \\
\hline \multicolumn{2}{|l|}{41} & \multicolumn{2}{|l|}{ skipped } & breakfast \\
\hline \multicolumn{2}{|l|}{ Actor } & \multicolumn{2}{|l|}{ Proc: Material } & Goal \\
\hline \multicolumn{2}{|l|}{ Subject } & \multicolumn{2}{|l|}{ Finite/Predicator } & Complement \\
\hline \multicolumn{2}{|l|}{ Theme } & \multicolumn{3}{|l|}{ Rheme } \\
\hline \multicolumn{5}{|c|}{ // $1 \wedge$ I/skipped /breakfast// } \\
\hline
\end{tabular}

Square brackets indicate ellipted items; Underlined syllables are tonic syllables as per the SFL system of intonation (see endnote 2 for more details on intonation analysis in SFL and notation conventions). See Halliday and Matthiessen 2014 for details on SFL lexicogrammatical analyses 
dining area. While he is walking, his friend, Monroe, comes up to him and speaks to him. He sees Monroe only after Monroe begins to speak. The complete dialogue of this scene can be divided into two main subject matters and two different activities with the first (clauses 1-4) segueing into the second (clauses 519). We first analyze and interpret clauses $1-4$ according to the material and the semiotic contexts. Table 1 displays the lexicogrammatical analysis.

\section{Excerpt two}

\section{Scene 1}

1 Monroe: Someone sure is hungry!

2 Ben: Hey Monroe. How you doing?

3 Monroe: Don't they feed you at home?

4 Ben: I skipped breakfast.

5 My mum's boyfriend took over the kitchen

6 and I walked out in protest.

7 Monroe: Well I could have told you

8 that was gonna happen.

9 Always does.

10 First thing they do is take over the bathroom and the kitchen.

11 Then the sofa and the TV.

$12 \mathrm{My}$ advice to you is to get rid of this guy, immediately.

13 Ben: It's gonna be pretty hard.

14 My mum's trapped in this huge love bubble.

15 She's not thinking clearly.

\section{Scene cont...}

16 Monroe: I'm telling you man,

17 whatever you do,

18 you'd better do it soon,

19 'cos it's my own personal experience that the longer a mum lives with a guy the harder it is to get rid of them.

(from Man of the House, Walt Disney Pictures)

I skipped breakfast (lines 1-4)

Material context

Monroe's utterance "Someone sure is hungry" is actually an oblique reference to the food on Ben's tray. However, Ben responds with, “Hey Monroe. How you doing?”. Ben's response, in contrast with Monroe's utterance is recognizable as a greeting. That Ben replies to Monroe's "someone sure is hungry" with a greeting suggests that Monroe's utterance is somehow functioning as a kind of greeting or a means of grabbing attention to himself, and of initiating an interaction, which are functions of a greeting. After Ben's reply, the dialogue continues with Monroe's question, "Don't they feed you at home?" 
Without access to the material setting and relying entirely on the language, the analyst must infer that Ben is eating, or about to eat because Monroe's attentionseeking greeting in which the "someone" is directed at Ben, and his continuation of the 'food' theme with the negative question "Don't they feed you at home?" is then followed by Ben's "I skipped breakfast", which uses past tense thus indicating something about an earlier opportunity to eat. Thus, the references to breakfast, hunger, and feeding, suggests that Ben is eating at the time that Monroe greets him, and that it is most likely morning (although we cannot be entirely sure. He could have skipped breakfast and it may now be lunch time). The language also indicates that the speakers are not at home. This interpretation derives from Monroe's question, “Don't they feed you at home?" The talk bears some of the hallmarks of spoken language, such as the use of "hey" and the use of first and second pronouns, and although these may be used in other situations, the initiating utterance by Monroe indicates a 'real-time' situation and that the speakers are in a face-to-face situation.

Thus from the opening few lines of this dialogue and from analyzing the language alone, we can glean something of the material context: it is most likely in the morning, in a location that is not Ben's home, where spoken, face-to-face talk while eating is possible, and that Ben is holding or in front of a lot of food that presumably he is eating or about to eat. Visual access to the material environment in fact confirms this.

In this excerpt the features of the material environment are not "there" in the text in the way the features of the material environment of the four garbage bins were referred to nor as a trace that interferes with the flow of the talk. Rather in this case, the material context has played a role in activating what is said; the speakers have mutual visible accessibility to the material environment, and it is this environment that motivates much of what they say: certainly it is the material environment, the food on Ben's tray that motivates Monroe's initial comment. This already-in-place material environment cannot be considered trivial to the linguistic choices made by the speakers. The question is, how should this be accounted for in the analysis? What is the relationship between the material environment and the talk? We return to answering these questions later.

\section{Semiotic context}

Let us now turn to the semiotic context as construed in the language. As already noted, Field, Tenor and Mode are realized through systematic choices in Experiential, Interpersonal and Textual meaning at the semantic level and through Transitivity, Mood and Theme at the lexicogrammatical level.

Field The first topic of the talk is primarily about food and it is construed through the use of lexical items and relations between participants in the clauses. The lexical items construing this subject matter are shown in bold font.

Relational Attributive Clause: A state of being: someone being hungry A Material Action: A third person (plural Actor) feeding "you" the addressee (Goal) 
A Material Action: The addressee (now the speaker-Actor) skipping breakfast (Goal)

While there is action being construed (feeding and skipping), there is no material action that the talk itself is facilitating (such as 'hand me that screwdriver'), thus the Action is classified as conceptual. The subject matter is about "home", and the daily act of being fed, or skipping meals, and hence the Sphere of Action is quotidian. This portion of the talk ends at "skipped breakfast" before the speakers embark on another topic, so the Performance of Action in this part of the activity can be said to be bounded.

Tenor As for the Tenor relations, the use of "sure" in "Someone sure is hungry" indicates an intensity of feeling on the part of the speaker to the situation (compare "someone's hungry"). The choice of a compound tone 53 on the opening ut-

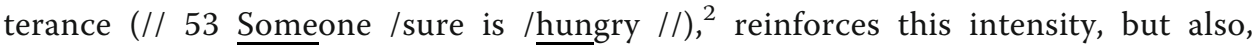
ending on a slight rising tone indicates some degree of enquiry into the situation, as a rising tone in general indicates incompleteness or uncertainty. Ben's response to Monroe's utterance with a tone 13 followed by a tone 1 on the whole greeting ('how you doing') effectively dismisses the enquiry, instead interpreting it as a

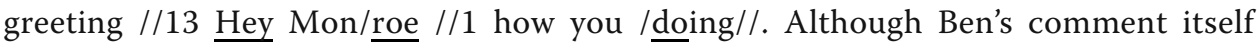
could be an initiating greeting, Monroe's "Someone sure is hungry" effectively fulfils the functions of a greeting, such as acknowledging another person, drawing attention to oneself typically before any other contact is made with the other person on that day (or occasion), and expressing a social relationship (such as close or distant, formal or informal) (cf. Goffman 1971). After Ben's response, however, Monroe, persists in his enquiry by ignoring Ben's greeting and not returning a response to his question (Compare: B: Hey Monroe. How you doing? M: Fine thanks). Instead, Monroe poses the question //2 Don't they /feed you at /home//. This is spoken on a steep rising Tone 2, the steep rise indicating he has raised the interpersonal involvement in his question, i.e. he REALLY wants to know.

In terms of social hierarchy, Monroe uses the language to enact an hierarchical relationship - that is, he is positioned as someone commenting on and enquiring about Ben. He wants to know what is going on with Ben and is demanding a response regarding Ben's unusual actions. The interpretation by Ben of Monroe's opening line as a greeting by responding "Hey Monroe, how you doing" enacts an acquired 'friend' social relation.

Mode With regard to the Mode, the use of the greeting "hey Monroe, how you doing?" which includes the word "hey", ellipsis of the auxiliary verb "are" in "are doing", and uses first and second person pronouns suggests this is a spoken dialogue and face to face (although, any of these could be used in written text, particularly via such media as a mobile phone or some other electronic social media device). The choices in Mode would be: [channel: linguistic, phonic]. As noted already, the language is not facilitating any kind of non-linguistic activity, and this indicates that the role of language in this situation is constitutive. 
Although we have separated the analysis into material and semiotic, we can see from the analysis of this part of the conversation that the material context impinges on the semiotic context, and together they construe the meanings that we have just discussed. While specific features of the material environment are not made explicit in the language, we can conclude from observing the scene and analyzing the language that both senses of context are in the language. This contrasts with the next part of the dialogue, analyzed in the next few paragraphs, wherein the material environment bears no relation to the talk at all.

\section{'My mum's boyfriend' (lines 5-19)}

The first part of the conversation shifts into Monroe and Ben talking about their respective experiences with their mothers' boyfriends. This is introduced with Ben's explanation for why he skipped breakfast: "My mum's boyfriend took over the kitchen and I walked out in protest". Table 2 (see Appendix) shows the lexicogrammatical analysis of this second part of the talk (clauses 5-19), and we will use this as the basis for making statements about the semantic choices and the contextual features relevant to this second part. As the mode essentially remains the same across each section of the dialogue, a description of the Mode for this second part of the dialogue is not included.

Field With regard to the experiential meanings, there are several processes which are repeated in this part of the dialogue, such as "take over". The meaning of 'take over' is to seize or capture, and in these clauses it is related as being acted out by persons other than the speakers but about items and situations within their experience, suggesting that it is a negative activity. The act of taking over itself is realized as not only a process in an independent clause but also as a process in an embedded clause. Ben says: "My mum's boyfriend took over the kitchen" and Monroe reiterates this idea in an embedded identifier (Value) in a Relational clause at line 10: "take over the bathroom and the kitchen", and in the next clause its meaning remains in the utterance "then [they take over] the sofa and the TV" through the cohesive device of ellipsis. In each of these cases the third party Actor doing the taking over is either "my mum's boyfriend" or "they" (referring to an unspecified group of people into which 'mum's boyfriend' would fit). The Goals in all these cases are rooms or objects in the home: bathroom and kitchen, sofa and TV (teevee). The second item in the pairs, 'bathroom and the kitchen' and 'sofa and teevee' is given tonic prominence and a falling tone, indicating a sense of definiteness and completion, with a high falling tone 1 on the word "teevee", which conveys a sense of alarm. In fact, Ben's mother's boyfriend's name is Jack, but notice that in his conversation with Monroe, Ben does not call Jack by his name but refers to him as "my mum's boyfriend", thus distancing himself somewhat from Jack and also denying Jack an identity outside his relationship with his mother. Jack is perceived as disconnected from Ben, too, because he is Ben's mother's boyfriend, and therefore only tangentially a part of Ben's world, or at least of Ben's desired world. 
There are some general Material processes, such as "do" and "happen". "Happen" in line 8 refers to Monroe's summing up of Ben's account of his mum's boyfriend taking over the kitchen. It is then elided in the utterance: "Always does [happen]". In the latter part of the dialogue, in lines 17 and 18, the verb "do" is used by Monroe to denote some kind of non-specific action that Ben should do in order to "get rid of" his mum's boyfriend. There are also Relational clauses used by Monroe in which he identifies certain actions and in doing so sets himself up as an authority on the subject of mother's boyfriends taking over the household: "The first thing they do IS" and "My advice to you IS".

Ben's response to Monroe's unsolicited advice to get rid of his mother's boyfriend "immediately" is presented through an Attributive clause; he says it's going to be "pretty hard". That is, he neither agrees nor disagrees with Monroe, nor does he commit himself to any specific action, unlike his earlier Actions of skipping breakfast and walking out in protest. The sudden switch to using an Attributive clause has the effect of halting Ben's actions with regard to the situation he is in, and making him appear somewhat reflective on the matter. He could have said, "Yeah, that's what I'm gonna do! I'll get rid of him" which would continue his earlier "rebellious" actions. Noteworthy is the fact that he divides the clause I walked out in protest into two pieces of information with tonic prominence (a falling tone) on both "out" and "protest". This construes an evaluative sense of boldness or bravado. But after Monroe gives his advice, Ben switches from Material clauses in which he is the Actor, to Relational clauses and Mental clauses. The first clause in his response, "it's gonna be pretty hard" is supported by two reasons presented in the next two clauses: A Relational clause in which his mother is the Carrier of the Attributive process of "trapped" and the Circumstance "in this huge love bubble". This clause is essentially an evaluation of his mother's state of being, but the next is a more overt evaluation of his mother's mental state through the Mental clause: "she's not thinking clearly". Thus, unlike Monroe whose advice does not take into account anyone else's feelings, Ben shows some consideration of his mother's feelings through these Relational clauses and the Mental clause, albeit from his own perspective.

Tenor In the scene, Monroe takes up the Transitivity function of "Sayer" with Ben as the Recipient: "I could have told you" and "I'm telling you man" and these clearly indicate that Monroe sees himself as the authority on the topic and qualified to tell Ben quite directly what he should be doing. Through these clauses he establishes his temporary social role and status as being 'adviser' to Ben. That is, he is not 'questioning' but 'telling' Ben what the situation is and what he needs to do about it. Monroe supports his own authority by relating his experience in the matter and through the use of the high value modal of usuality, "always" in "always does" (line 9). At the end of the conversation, he reiterates his role and experience in the matter through an identifying clause choosing to use an anticipatory "it" and loading the main crux of his message, the Value of the Token ("my own 
personal experience") into the 'New' position of the clause - at the end of the clause, thus highlighting again his view that Ben needs to get rid of his mum's boyfriend as soon as possible.

In this second part of the dialogue, the material context, as already noted, does not influence the talk at all, and its irrelevancy to the discourse is confirmed by the fact that the last few lines of the dialogue (clauses 16-19) actually take place in a completely different setting - along a school corridor. Thus, in this latter part of the dialogue the material and the semiotic contexts are separate and do not converge. [However, the fact that the speakers conduct their talk in a cafeteria and a school corridor rather than, say, in a classroom during class time, suggests that there may be a link between semiotic and material locations - i.e. certain material locations are more likely places for certain types of talk to occur. To explore this, however, would take a massive corpus of registers of talk with their physical locations described in order to discover such patterns. Such an analysis might give us very interesting insights about talk and location and society as a whole, but conducting such research is at present prohibitive due to a lack of technological resources for gathering such a corpus].

\section{Beyond the immediate context of situation and into the realm of culture}

Although I have tried not to, my analysis so far has possibly already gone beyond those contextual features that are directly found in the language of the text, but generally, I believe the analysis and interpretation have focused on what is directly construed by the language of the text. This section discusses some of the features of the talk that point to the way in which features of the material and semiotic contexts reach beyond the immediate context of situation. This involves an interpretation of the text by someone who is acculturated within the kind of cultural setting in which this text is embedded. It is, therefore, an interpretation that requires cultural background knowledge appropriate to the situation. To demonstrate the complex way in which culture is construed in language, in this discussion I focus primarily on just one line: Monroe's initial remark: "Someone sure is hungry".

There are various cultural allusions in this line which transcend the immediate context in which the interaction takes place. While the SFL model of context argues that the language of the situation gives access to the semiotic features of the context of situation, as already noted, there are factors that "leave a trace" in the text, but which are difficult to ascertain from the language alone (Bartlett 2013; Bowcher 2013, 2014; Hasan 2009). Bartlett discusses such allusions in terms of "environmental but non contextual factors" (Bartlett 2013:351). Monroe's utterance in clause 1 is a case in point. While his utterance alludes to the material situational setting as has been demonstrated, it is each participants' shared semiotic histories and shared cultural understandings which allow for the successful interpretation of Monroe's utterance as a greeting. These semiotic histories and shared cultural understandings perturb the potential context of situation and constrain the possible interpretations of the meaning of what is being said. That is, both Monroe and Ben allow the 
statement "Someone sure is hungry" to function in place of a more typical greeting such as "Hi Ben". Why? The answer may lie in the fact that this 'way' of greeting is richer in meaning than the phatic "Hi Ben" type. It is imbued with not only textual/discoursal meaning - it draws attention to Monroe and serves to begin an exchange - but with experiential meaning, in that it is effectively a comment on the amount of food on Ben's tray, an oblique comment on the fact that this is not Ben's usual practice, and an oblique and indirect enquiry into whether there is something going wrong in Ben's life. These underlying functions of the utterance overlap with the interpersonal meaning enacted in this comment. That is, what Monroe says to Ben indicates a personal relationship that is close and which allows for this kind of variation in greeting form. We could classify this close personal relationship as what Berry (2016) calls a "pretext relevant contextual feature". Such features, Berry explains "may not come before the text for the analyst, but ... they do for speakers and writers" (Berry 2016: 188).

While we can see that Ben interprets Monroe's utterance as a kind of greeting, we must reach into the 'strata' above (or perhaps surrounding) the immediate situation in order to interpret why it is that Ben 'knows' he can interpret Monroe's remark as a greeting. I presume that not all cultural settings would allow this kind of lexicogrammatical structure and content to function in the way that it does here (NB: there are other similar expressions such as "Someone's looking very dapper this morning" - a greeting/comment on a person's obviously new suit or particularly/atypically stylish clothing). And while most analysts would interpret Monroe's initial utterance as a kind of situated greeting, explaining why it is a greeting is more difficult. Simply saying, "well that's just the way it is in the cultural setting of these two young boys" is not satisfactory if one wishes to understand the relationship between language, context and culture. Such a response is akin to saying, we use the definite article "the" with "hospital" in "I'm going to the hospital" because that's just what we do in English. There is a cultural background which activates these kinds of choices, and it is this cultural background that the contextual features not only 'reach' into, but also depend upon. Within this cultural context, while most people would interpret the utterance as a greeting and unconsciously understand its underlying meanings, not everyone would be at liberty to use such an expression as a greeting. Thus, with regard to this one line, the shared subculture of the speakers and their interpersonal relations play a role in determining what they interpret, quite naturally, as a greeting. Moreover, to interpret Monroe's utterance "Someone sure is hungry" as a greeting is tightly bound to this context of situation. That is, it is in THIS specific context, this instance of the broader socio-cultural context, that its semiotic role is that of a greeting, and it is because of the material environment that the utterance comes into play in the way that it does. This is evident when one considers that in some other kind of context the utterance, albeit most likely with a different intonational character, might be a comment on a different state of affairs: one sees that a person at the dinner table has eaten everything on his plate, and the comment is made, and cannot be interpreted as a greeting! 


\section{Conclusion}

The analysis of Excerpt Two has shown that the material elements of the context, e.g. the tray filled with food and the location of the interaction, are key to interpreting what is going on in the beginning of the exchange, the semiotic context, even though those material elements are not, in fact, picked up in the language of the text in any explicit way. Further, the analysis and discussion of the text has ultimately shown how the two different 'senses' of context, the material and the semiotic, converge and reach into the cultural context in which the situation is embedded to construe a culturally accepted 'greeting', rich with meaning. I am not alone in suggesting that there are different 'reaches' of context that are realized in a text. As already mentioned, Bartlett's (2013, 2016, 2017) and Berry's (2016) recent work also explores this idea, although they do not use the term 'reach'. While the analysis and interpretation of just one line of the dialogue demonstrates the rich relationship between language, context and culture, there remains the issue of how to organize and model such an analysis and interpretation. In his multiscalar model, Bartlett (e.g. Bartlett 2016, 2017) has proposed four concepts that might be useful in this regard: 'activation' (the influence of any feature of the environment on any aspect of a text whether that be covert or overt), 'construal' (the way in which contextual features can be explicitly "read off" the text), 'correlation' (the "tendencies" for certain language features to "cooccur" with certain environmental features) and 'indexicality' ("ways of speaking" associated with socially established activities or groups of people) (see Bartlett 2017: 385-6). A critical appraisal and application of Bartlett's concepts was not within the scope of this paper, but we can see from the few texts analyzed within this paper, and of course other analyses across the SFL literature that the relationship between the material and the semiotic varies in interesting and sometimes quite complex ways depending on the situation, and that these two senses of context, rather than being in opposition to each other, may converge to realize specific cultural phenomena.

\section{Endnotes}

${ }^{1}$ I wish to thank Professor Xuanwei (Alex) Peng for inviting me to speak at the Inaugural Halliday \& Hasan Forum at Guangdong University of Foreign Studies, Guangzhou, China, 3-4 December, 2016. The full title of the Forum was: "The Inaugural Halliday-Hasan Lectures and International Forum on Language: Studying Language in Context: Exploring SFL Advances in Theorizing and Appliability".

${ }^{2}$ Clauses are analyzed according to the SFL intonation system. Tone 1: falling tone, Tone 2: rising tone, Tone 3: level/low rising, Tone 4: falling-rising (rounded), Tone 5: rising-falling (rounded), Tone 13: compound tone - falling then low rising, Tone 53: compound tone - rising-falling (rounded) then low rising; single forward slash means foot boundary, double forward slash means tone group boundary, an underlined syllable is the tonic syllable. For a full explanation of the SFL system of intonation, see Halliday and Greaves (2008) or Bowcher and Debashish (in press). 


\section{Appendix}

Table 2 Lexicogrammatical and intonation analysis of the second part of the talk between Ben and Monroe (Clauses 5-19)

\begin{tabular}{|c|c|c|c|c|c|}
\hline $\begin{array}{l}5 \text { My mum's } \\
\text { boyfriend }\end{array}$ & took over & & the kitchen & & \\
\hline Actor & Proc: Materia & & Goal & & \\
\hline Subject & Finite/Pred & & Complement & & \\
\hline Theme (topical) & Rheme & & & & \\
\hline \multicolumn{6}{|c|}{ //1 ^ my /mum's /boyfriend // $1 \wedge$ took /over the /kitchen// } \\
\hline \multirow[t]{3}{*}{6 and } & । & $\begin{array}{l}\text { walked } \\
\text { out }\end{array}$ & in protest & & \\
\hline & Actor & $\begin{array}{l}\text { Proc: } \\
\text { Material }\end{array}$ & Circ: Manner & & \\
\hline & Subject & $\begin{array}{l}\text { Finite/ } \\
\text { Pred }\end{array}$ & Adjunct & & \\
\hline Theme (textual) & $\begin{array}{l}\text { Theme } \\
\text { (topical) }\end{array}$ & Rheme & & & \\
\hline \multicolumn{6}{|c|}{ Theme } \\
\hline \multicolumn{6}{|c|}{$/ / 1 \wedge$ and I /walked /out in // 1 protest// } \\
\hline \multirow[t]{3}{*}{7 Well } & I & could & have told & you & $\begin{array}{l}\text { that was gonna [going to] } \\
\text { happen }\end{array}$ \\
\hline & Sayer & Proc: Verbal & & Receiver & Verbiage \\
\hline & Subject & $\begin{array}{l}\text { Finite } \\
\text { (modal) }\end{array}$ & Predicator & Complement & \\
\hline Theme (textual) & $\begin{array}{l}\text { Theme } \\
\text { (topical) }\end{array}$ & Rheme & & & \\
\hline
\end{tabular}

//53 ^ well I /could have /told you /that was /gonna /happen//

\begin{tabular}{|c|c|c|c|}
\hline \multirow[t]{4}{*}{8 [that] } & that & was & gonna [going to] happen \\
\hline & Actor & \multicolumn{2}{|c|}{ Proc: Material } \\
\hline & Subject & Finite & Predicator \\
\hline & $\begin{array}{l}\text { Theme } \\
\text { (topical) }\end{array}$ & Rheme & \\
\hline 9 [it] & always & & does \\
\hline Proc: Actor & & & Proc: Material \\
\hline Subject & \multicolumn{2}{|c|}{ Mood Adjunct: usuality } & Finite \\
\hline \multirow[t]{2}{*}{ Theme } & \multicolumn{3}{|l|}{ Rheme } \\
\hline & \multicolumn{3}{|c|}{ //5 always /does// } \\
\hline $\begin{array}{l}10 \text { first thing } \\
\text { they do }\end{array}$ & \multicolumn{2}{|l|}{ is } & take over the bathroom and the kitchen \\
\hline Token & \multicolumn{2}{|c|}{ Proc: Relational } & Value \\
\hline Subject & \multicolumn{2}{|l|}{ Finite } & Complement \\
\hline Theme & \multicolumn{3}{|l|}{ Rheme } \\
\hline
\end{tabular}


Table 2 Lexicogrammatical and intonation analysis of the second part of the talk between Ben and Monroe (Clauses 5-19) (Continued)

\begin{tabular}{|c|c|c|c|c|c|}
\hline 11 then & \multicolumn{2}{|l|}{ [they } & \multicolumn{2}{|l|}{ take over] } & the sofa and the tv \\
\hline Circum: temporal & \multicolumn{2}{|l|}{ [Actor $]$} & \multicolumn{2}{|l|}{ [Proc: Material] } & Goal \\
\hline Adjunct & \multicolumn{2}{|l|}{ [Subject] } & \multicolumn{2}{|l|}{ [Finite] } & Complement \\
\hline Theme (topical) & \multicolumn{2}{|l|}{ Rheme } & & & \\
\hline \multicolumn{6}{|c|}{$/ / 1+\Lambda$ then the /sofa and the /teevee// } \\
\hline $\begin{array}{l}12 \text { my advice to } \\
\text { you }\end{array}$ & \multicolumn{2}{|l|}{ is } & to get rid of this guy & \multicolumn{2}{|l|}{ immediately } \\
\hline Token & \multicolumn{2}{|l|}{ Proc: Relational } & Value & \multicolumn{2}{|l|}{ Cir: temporal } \\
\hline Subject & \multicolumn{2}{|l|}{ Finite } & Complement & \multicolumn{2}{|l|}{ Adjunct } \\
\hline Theme & \multicolumn{2}{|l|}{ Rheme } & & & \\
\hline \multicolumn{6}{|c|}{$/ / 1 \mathrm{my}$ ad/vice to /you is to /get /rid of this/guy// $1 \wedge \mathrm{im} /$ mediately// } \\
\hline \multicolumn{2}{|l|}{13 it } & 's & gonna be & \multicolumn{2}{|l|}{ pretty hard } \\
\hline \multicolumn{2}{|l|}{ Carrier } & \multicolumn{2}{|c|}{ Proc: Relational } & \multicolumn{2}{|l|}{ Attribute } \\
\hline \multicolumn{2}{|l|}{ Subject } & Finite & \multirow[t]{3}{*}{ Predicator } & \multicolumn{2}{|l|}{ Complement } \\
\hline Theme & & Rheme & & & \\
\hline \multicolumn{5}{|c|}{$/ / 1 \wedge$ it's /gonna be /pretty /hard// } & \\
\hline \multicolumn{2}{|l|}{14 My mum } & 's & trapped & \multicolumn{2}{|c|}{ in this huge love bubble } \\
\hline Carrier & & Proc: Relatio & nal (Attributive) & Cir: location & \\
\hline Subject & & Finite & Predicator & Adjunct & \\
\hline Theme & & Rheme & & & \\
\hline$/ / 5 \wedge \mathrm{my} / \mathrm{mum}^{\prime} \mathrm{s}$ & trapped in this & /huge /love & /bubble// & & \\
\hline 15 She & & 's not & thinking & clearly & \\
\hline Senser & & Proc: Mental & & Cir: Manner & \\
\hline Subject & & Finite & Predicator & Adjunct & \\
\hline Theme & & Rheme & & & \\
\hline$/ / 1 \wedge$ she's $/$ not $/ \mathrm{tl}$ & inking /clearly/ & & & & \\
\hline 161 & & 'm & telling & you & man \\
\hline Sayer & & Proc: verbal & & Receiver & \\
\hline Subject & & Finite & Predicator & Complement & Vocative \\
\hline Theme & & Rheme & & & \\
\hline$/ / 13 \wedge$ I'm /telling & you /man// & & & & \\
\hline 17 whatever & & you & & do & \\
\hline Goal & & Actor & & Proc: Material & \\
\hline Complement & & Subject & & Finite & \\
\hline Theme & & Rheme & & & \\
\hline$/ / 3 \wedge$ what/ever yc & u /do// & & & & \\
\hline 18 you & 'd better & do & it & soon & \\
\hline Actor & Proc: Material & & Goal & Cir: temporal & \\
\hline Subject & Finite(modal) & Predicator & Complement & Adjunct & \\
\hline Theme & Rheme & & & & \\
\hline
\end{tabular}


Table 2 Lexicogrammatical and intonation analysis of the second part of the talk between Ben and Monroe (Clauses 5-19) (Continued)

\begin{tabular}{|c|c|c|c|c|}
\hline \multicolumn{5}{|c|}{$/ / 1 \wedge$ you'd /better /do it /soon// } \\
\hline \multirow[t]{3}{*}{$19^{\prime} \cos$ [because] } & it & 's & $\begin{array}{l}\text { my own personal } \\
\text { experience }\end{array}$ & $\begin{array}{l}\text { that the longer a mum lives with a guy } \\
\text { the harder it is to get rid of them }\end{array}$ \\
\hline & Value & Proc: Relat & Token & Value cont... \\
\hline & Subject & Finite & Complement & Subject cont... \\
\hline Theme (textual) & $\begin{array}{l}\text { Theme } \\
\text { (topical) }\end{array}$ & & & \\
\hline Them & & Rheme & & \\
\hline
\end{tabular}

//3 cos it's my /own /personal ex/perience // $3 \wedge$ that the /longer a /mum /lives with a /guy // $5 \wedge$ the /harder it /is to get /rid of them//

\begin{abstract}
Square brackets indicate ellipted or reduced items; Underlined syllables are tonic syllables as per the SFL system of intonation (see endnote 2 for more details on intonation analysis in SFL and notation conventions). See Halliday and Matthiessen 2014 for details on SFL lexicogrammatical analyses
\end{abstract}

\title{
Acknowledgements
}

N/A

\section{Funding}

N/A

\section{Availability of data and materials}

N/A

\section{Authors' contributions}

Wendy Bowcher is the sole author. The author read and approved the final manuscript.

\section{Competing interests}

The author declares that he/she has no competing interests.

Received: 25 January 2018 Accepted: 5 March 2018

Published online: 06 April 2018

\section{References}

Bartlett, T. 2013. I'll manage the context: Context, environment and the potential for institutional change. In Systemic Functional Linguistics: Exploring Choice, ed. L. Fontaine, T. Bartlett, and G. O'Grady, 342-364. Cambridge: Cambridge University Press.

Bartlett, T. 2016. Multiscalar modelling of context: Some questions raised by the category of mode. In Society in Language: Language in society: Essays in honour of Ruqaiya Hasan, ed. W.L. Bowcher and J.Y. Liang, 166-183. Basingstoke: Palgrave.

Bartlett, T. 2017. Context in systemic functional linguistics: Towards a scalar supervenience. In The Routledge Handbook of Systemic Functional Linguistics, ed. T. Bartlett and G. O'Grady, 375-390. London: Routledge.

Berry, M. 2016. On describing contexts of situation. In Society in Language: Language in Society: Essays in Honour of Ruqaiya Hasan, ed. W.L. Bowcher and J.Y. Liang, 184-205. Basingstoke: Palgrave.

Bowcher, W.L. 1999. Investigating institutionalization in context. In Text and context in functional linguistics, ed. M. Ghadessy, 141-176. Amsterdam: John Benjamins.

Bowcher, W.L. 2007. Field and multimodal texts. In Continuing discourse on language, volume 2, ed. R. Hasan, C.M.I.M. Matthiessen, and J.J. Webster, 619-646. London: Equinox.

Bowcher, W.L. 2013. Material action as choice in field. In Systemic Functional Linguistics: Exploring Choice, ed. L. Fontaine, T. Bartlett, and G. O'Grady, 318-241. Cambridge: Cambridge University Press.

Bowcher, W.L. 2014. Issues in developing unified systems for contextual field and mode. Functions of Language 21 (2): 176-209.

Bowcher, W.L., and M. Debashish. In press. Intonation. In The Cambridge Handbook of Systemic Functional Linguistics, ed. G. Thompson, W.L. Bowcher, L. Fontaine, and D. Schönthal. Cambridge: Cambridge University Press.

Ervin-Tripp, S. 1996. Context in language. In Social interactions, social context, and language, ed. D.I. Slobin, J. Gerhardt, A. Kyratzis, and J. Guo, 21-36. Hillsdale: Lawrence Erlbaum Associates.

Goffman, I. 1971. Relations in public: Microstudies of the public order. London: Routledge.

Halliday, M.A.K. 1977. Text as semantic choice in social contexts. In Grammars and descriptions, ed. T. van Dijk and J. Petöfi, 176-225. Berlin: Walter de Gruyter

Halliday, M.A.K. 1984. Language as code and language as behavior: A systemic-functional interpretation of the nature and ontogenesis of dialogue. In The Semiotics of Culture and Language. Volume 1: Language as Social Semiotic, ed. R. Fawcett, M.A.K. Halliday, S. Lamb, and A. Makkai, 3-35. London: Pinter. 
Halliday, M.A.K. 1985. Part A in M.A.K. Halliday and R. Hasan. In Language, Context and Text: Aspects of Language in a Social-semiotic Perspective, 3-49. Geelong: Deakin University Press.

Halliday, M.A.K. 2007. The notion of 'context' in language education. In Language and education, volume 9 in the collected works of M.A.K. Halliday, ed. Jonathan J. Webster, 269-290. London: Equinox.

Halliday, M.A.K., and W.S. Greaves. 2008. Intonation in the grammar of English. London: Equinox.

Hasan, R. 1981. What's going on: A dynamic view of context in language. In The seventh LACUS forum 1980, ed. J.E. Copeland and P.W. Davis, 106-121. Columbia: Hornbeam Press.

Hasan, R. 1995. The conception of context in text. In Discourse in society: Systemic functional perspectives: Meaning and choice in language: Studies for Michael Halliday, ed. P. Fries and M. Gregory, 183-283. New Jersey: Ablex.

Hasan, R. 2001. Wherefore context? The place of context in the system and process of language. In Grammar and Discourse: Proceedings of the International Conference on Discourse Analysis, ed. R. Shaozeng, W. Guthrie, and I.I.R. Fong, 1-21. Macau: Publication Centre, University of Macau.

Hasan, R. 2009. The place of context in a systemic functional model. In Continuum Companion to Systemic Functional Linguistics, ed. M.A.K. Halliday and J.J. Webster, 166-189. London: Continuum [now published by Bloomsbury].

Hasan, R. 2014. Towards a paradigmatic description of context: Systems, metafunctions, and semantics. Functional Linguistics 1 (9): 1-54.

Submit your manuscript to a SpringerOpen ${ }^{\circ}$ journal and benefit from:

- Convenient online submission

- Rigorous peer review

- Open access: articles freely available online

- High visibility within the field

- Retaining the copyright to your article

Submit your next manuscript at $\gg$ springeropen.com 